\title{
Intradermal Nevus
}

National Cancer Institute

\section{Source}

National Cancer Institute. Intradermal Nevus. NCI Thesaurus. Code C3804.

A nevus characterized by the proliferation of nevus cells in the dermis without involvement of the dermal-epidermal junction. 